\title{
Influence of the Fuel Properties on the Injection Process and Spray Development in a Large Ship Diesel Engine
}

\author{
I. Najar ${ }^{* 1}$ B. Buchholz ${ }^{1}$, B. Stengel ${ }^{1}$, C. Fink ${ }^{1}$, E. Hassel ${ }^{2}$ \\ ${ }^{1}$ Institute of Piston Machines and Internal Combustion Engines, Rostock University, Germany \\ ${ }^{2}$ Department of Technical Thermodynamics, Rostock University, Germany \\ *Corresponding author: ibrahim.najar2@uni-rostock.de
}

\begin{abstract}
The present paper deals with the influence of fuel properties on the spray behaviour. This influence was studied experimentally using a common rail injection system from a medium speed diesel engine. The experiments have been performed with diesel fuel (EN-590) and heavy fuel oil (RMG 180) on a constant volume chamber at room temperature. Comparison of the spray characteristics shows that the heavy fuel oil penetrates deeper in the chamber. However, the diesel spray has a bigger cone angle. These results formed the basis for a further development of the 1D-model [1] to predict the spray penetration by considering the fuel properties and temperature.
\end{abstract}

\section{Keywords}

Fuel properties, Diesel, Heavy Fuel Oil, Injection, 1D-Spray Model.

\section{Introduction}

The dependency of mixture formation on fuel properties is known and investigated by several researchers e.g. [25]. In [2] different biodiesel blends $\left(B_{5}, B_{10}, B_{20}\right.$ and $\left.B_{50}\right)$ in diesel fuel, pure biodiesel $\left(B_{100}\right)$ and diesel fuel were experimentally examined in a cold chamber (room temperature) and on a single-cylinder diesel engine. The study shows that the physical properties of biodiesel and its blends influence the spray breakup as well as the emissions output. It was also noticed that the bigger the proportion of the biodiesel the longer the spray tip penetration. This result agrees with those in [3]-[5] and [14]. In [14] leads an increase in the fuel density to increase the spray length and decrease in the spray cone angle in the fully developed zone. A similar influence has the fuel viscosity in the same zone. Besides the influence on the spray development, the fuel physical properties affect the hydraulic behaviour of the injector and thus on the injection rate and injection duration. Increasing the fuel density leads to a higher injection rate [12], [14-15], which can be theoretically concluded from Bernoulli's equation. Viscosity influence on the hydraulic behaviour of the injector is more complicated which causes a discrepancy in literature. For too small injection quantities the dynamic of the injector needle is affected by fuel viscosity which changes the injection rate shape and timing [16]. If the injector needle reaches its highest position than the close curve depends on the viscosity [17]. This phenomenon could not be noticed in [15] and [18].

The introduction of the IMO-TIER-III emission legislation demands a drastic reduction of $\mathrm{NO}_{\mathrm{x}}$-emission within the $\mathrm{NO}_{x}$ Emission Control Areas (NECAs). The demanded reduction can only be made by developing and introducing novel technologies for ship diesel engines. The discussed strategies for $\mathrm{NO}_{\mathrm{x}}$-reduction is based on different technologies from automotive sector which usually can be realized only by the use of distillate fuels. Outside these control areas, IMO-TIER-II limits are applied and in force. This legislation can be achieved by utilizing engine internal measures such as miller cycle combined with high pressure intake air, heavy fuel oil and common rail injection system. HFO and the distillate fuels have different physical properties which affect the spray structure, and thus, the combustion and the emission formation as well. Therefore, the relationship between the physical properties of the fuel and the development of spray structure has been experimentally investigated using HFO (RMG 180) and diesel fuel (EN-590). Table 1 presents the corresponding physical properties of the HFO (RMG 180) and the diesel fuel.

\section{Experimental setup}

Injection experiments were carried out using a large engine solenoid valve CR-injector with integrated fuel reservoir and a nozzle containing eight cylindrical holes. The injector can be operated with both distillate fuel as well as heavy fuel oil (HFO). Injection rate measurements were performed using an injection rate analyser [7] (based on $\mathrm{BOSCH}$ principle [8]), Figure 1. Fuel spray characteristics were quantified using a high-pressure/high-temperature chamber [9] with optical access, Figure 1. The chamber can be operated at a constant flow of nitrogen at temperatures and pressures up to $900 \mathrm{~K}$ and 40 bar. For optical accessibility the chamber is equipped with three windows while the injector was mounted with a customized flange to achieve a full frame of one injection jet for analysis with a maximum length of $130 \mathrm{~mm}$. The other injection jets were hidden using a deflection cap that was mounted on the injector tip. 
The injector was operated with diesel fuel (DF) according to DIN EN-590 specification and with heavy fuel oil (RMG 180), Table 1. In order to assure a typical injection viscosity during heavy fuel oil operation the fuel system was heated properly using electrical heating. Furthermore, the injector temperature was controlled using heated oil in the area of the nozzle.

For quantification of the spray characteristics in terms of spray penetration and spray cone angle image sequences were taken at cold chamber conditions (room temperature) using a Phantom V7.2 high-speed camera. The images have a resolution of $800 \times 300 \mathrm{px}$ and were recorded at a frame frequency of up to $12820 \mathrm{kHz}$ and shutter times $\leq$ 5 us. For proper lightning of the injection jet two xenon flashes were mounted orthogonally to the camera, Figure 2. Injection and camera were controlled via a main test bench computer. To avoid shot-to-shot deviations results of at least 10 injections were averaged. Jet volume was calculated through a numeric rotation of the jet profile defined by the measured spray penetration and spray cone angle. The operating pints used in the current study to validate and modify the spray model are shown in Table 2.

Table 1. Test fuel properties during injection tests. *values from DIN EN 590 fuel specification

\begin{tabular}{l|ll}
\hline \hline & DF $($ EN 590) & HFO (RMG 180) \\
\hline \hline Density $\left[\mathrm{kg} / \mathrm{m}^{3}\right]$ & $820-845\left(15^{\circ} \mathrm{C}\right)^{\star}$ & $995\left(50^{\circ} \mathrm{C}\right)$ \\
Viscosity $[\mathrm{cSt}]$ & $<4,5\left(40{ }^{\circ} \mathrm{C}\right)^{*}$ & $12\left(120^{\circ} \mathrm{C}\right)$ \\
Operation temperature $\left[{ }^{\circ} \mathrm{C}\right]$ & 40 & 120
\end{tabular}

\begin{tabular}{ccc}
\multicolumn{3}{c}{ Table 2. Test Matrix } \\
\hline \hline PInj in bar & $\rho_{g}$ in $\mathrm{kg} / \mathrm{m}^{3}$ & $T_{g}$ in $\mathrm{K}$ \\
\hline \hline 800 & 22 and 33 & 293 \\
1600 & 22 and 33 & 293 \\
1800 & 22 and 33 & 293
\end{tabular}

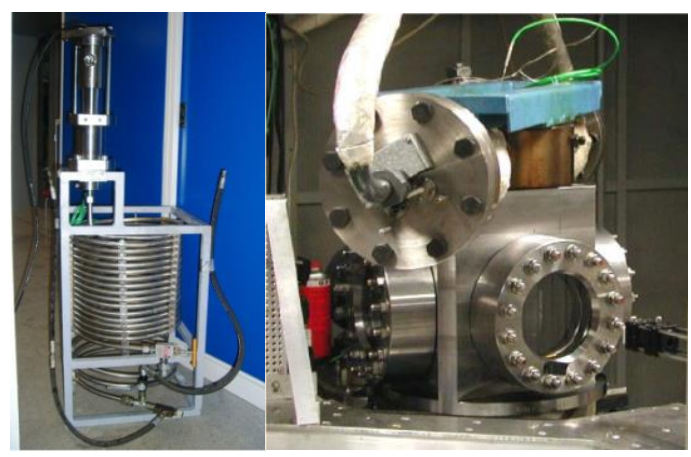

Figure 1. (Left) Injection rate analyser, (Right) high-pressure/high-temperature injection chamber
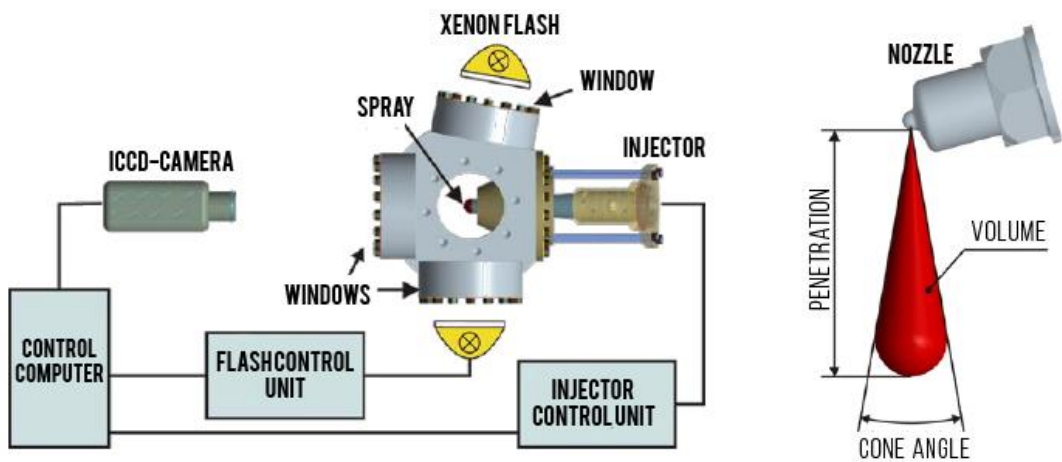

Figure 2. (Left) Schematic layout of scatter light measurements, (Right) definition of jet parameters

\section{D-modell to predict the spray tip penetration}

The empiric model in [1] bases on two phenomena, which were noticed in a framework of an experimentally analysis of the mixture formation at medium speed diesel engines [6]. First, it has been noticed that the spray penetration from a nozzle hole depends only on the gas density and the cumulated injected mass, Figure 3. Furthermore, the 
correlation between the spray penetration and the cumulated injected mass proves to be valid regardless of the injection pressure, the nozzle holder and the nozzle geometry [1]. The left diagram in Figure 3 reveals the known influence of the injection pressure on spray length. Rising the injection pressure leads to a faster penetration. If the penetration was plotted over the cumulated injected mass per nozzle hole, then the injection pressure has no influence on the spray penetration, which can be recognized in the right diagram in Figure 3.
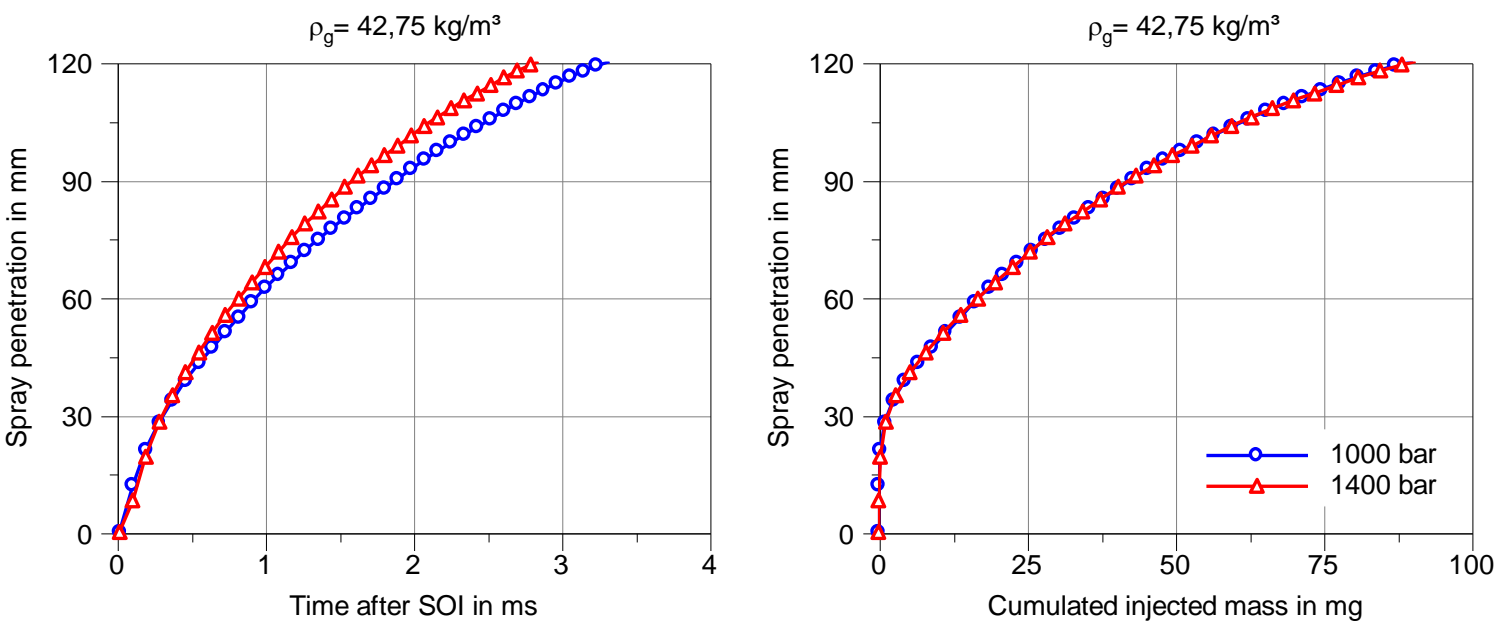

Figure 3. Plot of Spray penetration at 1000 bar and 1400 bar rail pressure against time (Left) and against cumulated injection mass per nozzle hole (Right)
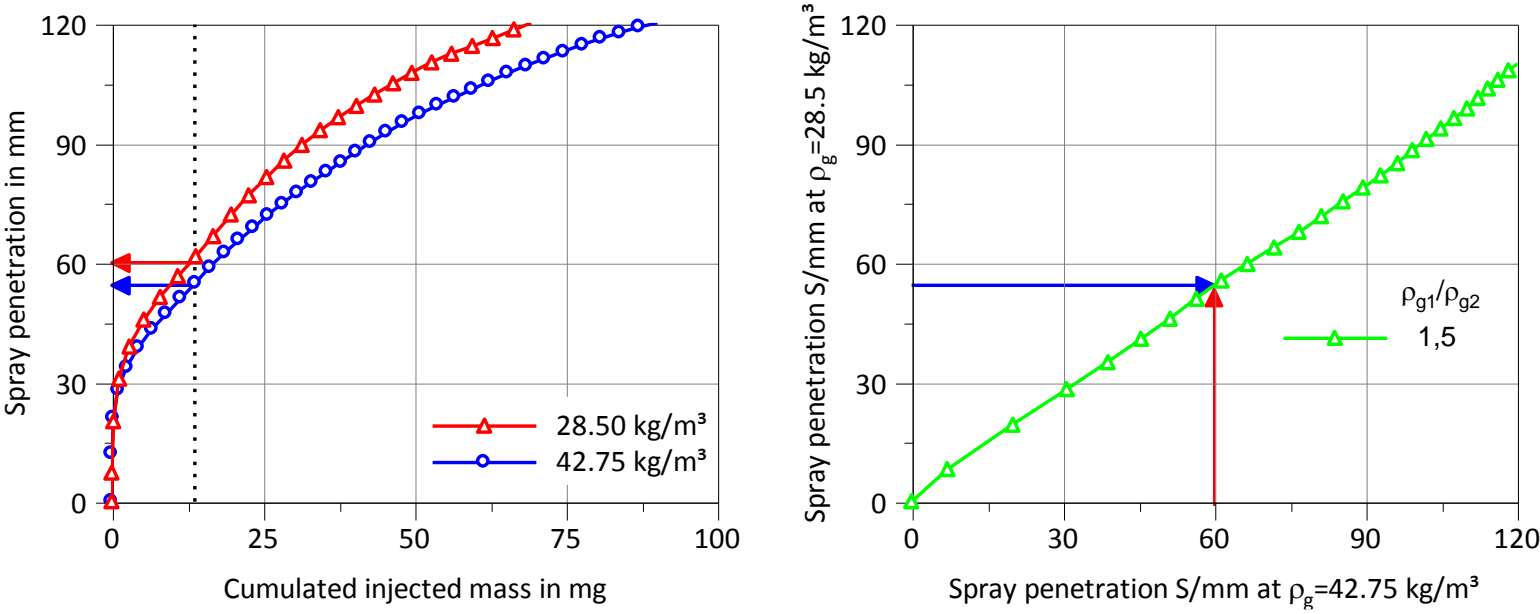

Figure 4. Spray penetration at 28.5 and $42.75 \mathrm{~kg} / \mathrm{m}^{3}$ against the cumulated injected mass (Left), and against each other (Right)

The second phenomenon includes the influence of the gas density on the spray tip penetration. To investigate this influence spray penetration at gas density $\rho_{2}$ (As an example $28.5 \mathrm{~kg} / \mathrm{m}^{3}$ in Figure 4) has been plotted over another penetration at different gas density $\rho_{1}\left(42.75 \mathrm{~kg} / \mathrm{m}^{3}\right.$ in the same figure) at the same cumulated injected mass (notice the red and the blue arrow). The relationship between these two penetrations seems to be linear, as can be seen from the previous figure (Right). The linear curve slope changes with the gas densities and depends only on the density ratio, see Figure 5 .

At the end the spray penetration can be calculated as a function of the cumulated injected mass, the hydraulic flow rate and gas density, equation 1 . The hydraulic flow rate as well as the cumulated mass are taken for one hole not the whole nozzle. This means, that the used cumulated injected mass should be equal to the cumulated injected mass of the whole nozzle divided by number of the nozzle holes. The model coefficients from equation 1 were determined to be $a=265.7, b=0.445$ and $c=-0.387$ with fuel temperature of $40^{\circ} \mathrm{C}$. It can be shown that the coefficients are the same for all analyzed nozzles and injectors. More details about the deviation of equation 1 and its validation can be found in [1].

$$
S_{\rho_{g}}=a \cdot\left(\frac{m_{f}}{\sqrt{Q_{h y d}}}\right)^{b} \cdot \rho_{g}^{c}
$$


Under the assumption that the injection rate is constant and using for example the model from Naber and Siebers [19], which is based on momentum conservation, a similar equation can be derived, equation 2 , which validates this model.

$$
S_{\rho_{g}} \propto\left(\frac{m_{f}}{\sqrt{Q_{h y d}}}\right)^{b 1} \cdot\left(\rho_{f} \cdot \rho_{g}\right)^{c 1}
$$

The coefficients $b_{1}$ and $c_{1}$ are 0.5 and -0.25 respectively, and as can be noticed they are similar to empirical values in equation 1 . Although that the fluid density $\rho_{f}$ shows up explicitly in equation 2 , it is expected a better agreement between the measured and using equation 1 calculated penetrations. The reason for this lies in considering the transient behaviour of the injection rate during the opening and closing phase and thus the hydraulic of the injector. Furthermore, equation 1 considers implicitly not only the fuel density but also its surface tension by the coefficient $a$. This dependency will be explained later, see equation 3. Moreover the coefficient $a$ has the same value for all nozzles and remains the same for different injector types and designs [1], which is not the case in equation 2.

Equation 1 was developed and validated for diesel fuel at fuel temperature of $40^{\circ} \mathrm{C}$. To use this model with other fuels and/or at different fluid temperature the model coefficients should be modified.

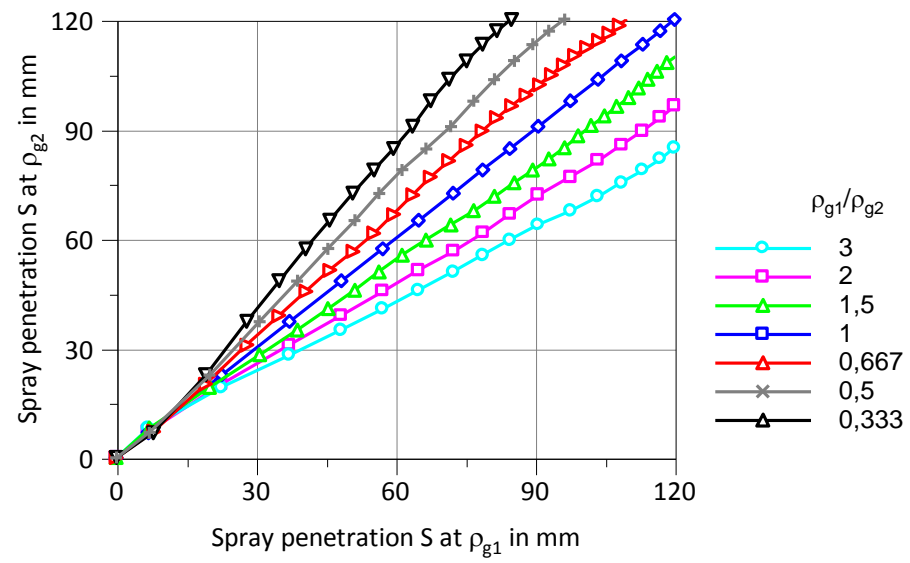

Figure 5. Correlation of spray penetrations at different gas densities at times of equal cumulated mass
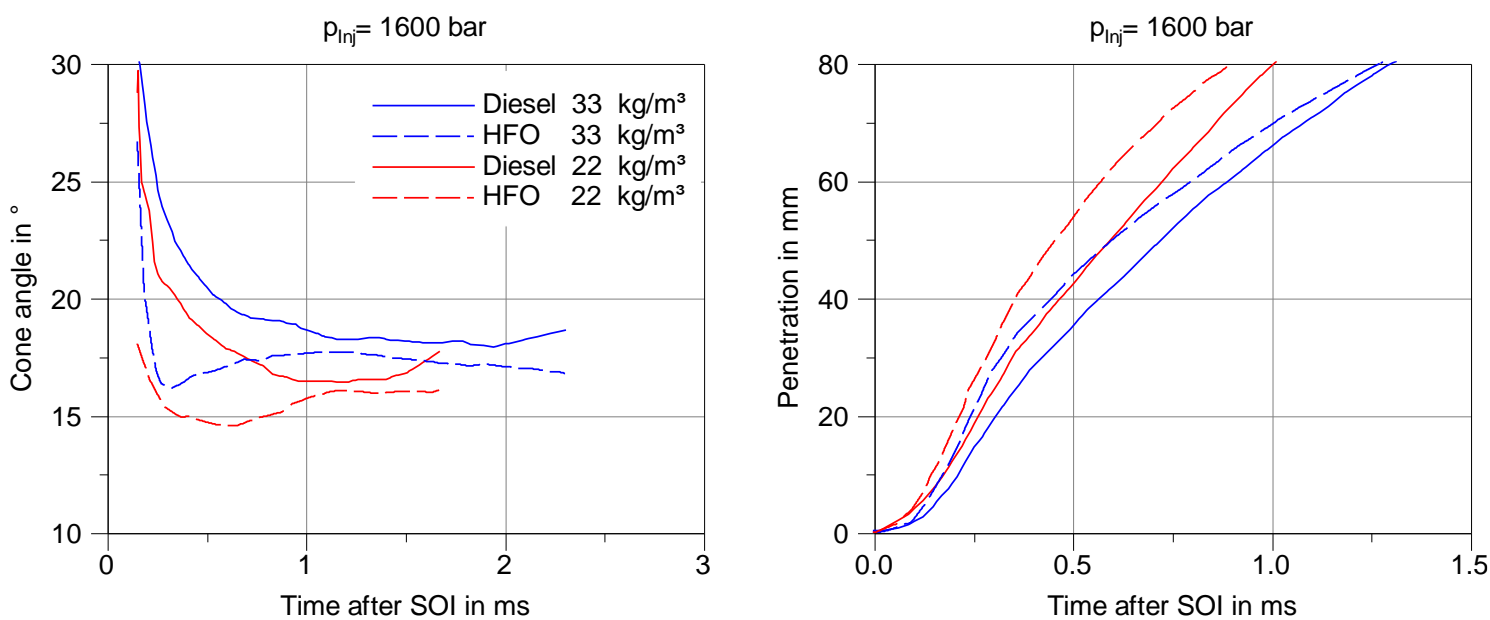

Figure 6. Cone angle and spray penetrations of the two fuels at varying gas densities and 1600 bar injection pressure

\section{Experimental and numerical results}

Figure 6 presents the development of the measured spray tip penetration and cone angle of diesel fuel and HFO at 1600 bar and two gas densities 22 and $33 \mathrm{~kg} / \mathrm{m}^{3}$. The standard deviation of the measurement is lower than $2 \mathrm{~mm}$ and $1.5^{\circ}$ for spray penetration and cone angle respectively. Due to the high surface tension i.e. low We-number of HFO its primary break up results in bigger droplets and ligaments with more inertia than by diesel fuel. This leads to a longer spray penetration. However, the diesel obtains a higher cone angle. To explain this the nozzle flow has been simulated using the commercial CFD-code AVL-FIRE. 
To calculate the needle lift curve, which is needed for the nozzle flow simulation, a 1D-hydraulic-model of the injector was developed using the program AVL BOOST HYDSIM and subsequently calibrated with utilizing the measurements on the injection rate analyzer. Figure 7 presents a comparison of a calculated and measured injection rate and also a comparison between calculated and measured injected mass at different injector actuation time. As can be seen, the data agrees very well. The deviation of the cumulated injection mass is less than $5 \%$ which lies in the range of the measurement accuracy.

The CFD-simulation of the nozzle flow shows that turbulent kinetic energy at the nozzle outlet in diesel case is much larger than in HFO-case, Figure 8. The high viscosity of the heavy fuel oil suppresses the formation of cavitation. In diesel case the fuel vapour reaches the hole outlet, Figure 8. Collapsing of the cavitation bubbles in diesel case enhances the turbulence and the radial components of the velocity which increase the initial angle of the spray. Furthermore the low value of turbulent kinetic energy and the high viscosity of the heavy fuel lead to a compact spray core with a lower air entrainment in the spray and thus to a low cone angle value.
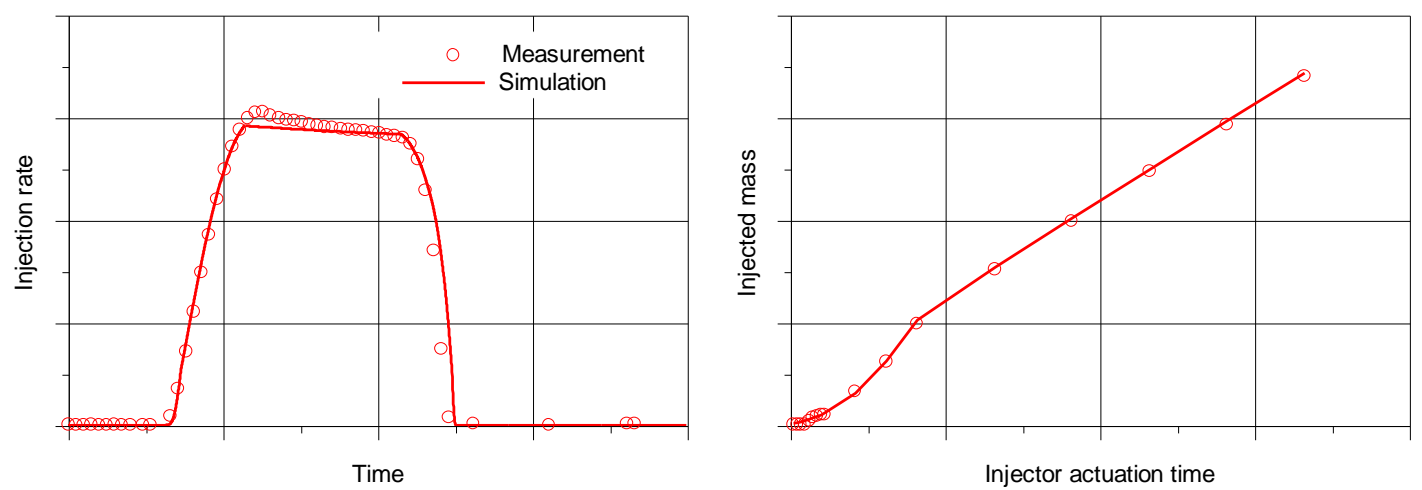

Figure 7. Comparison of the measured and calculated injection rate (Left) and the injected mass at different actuation time
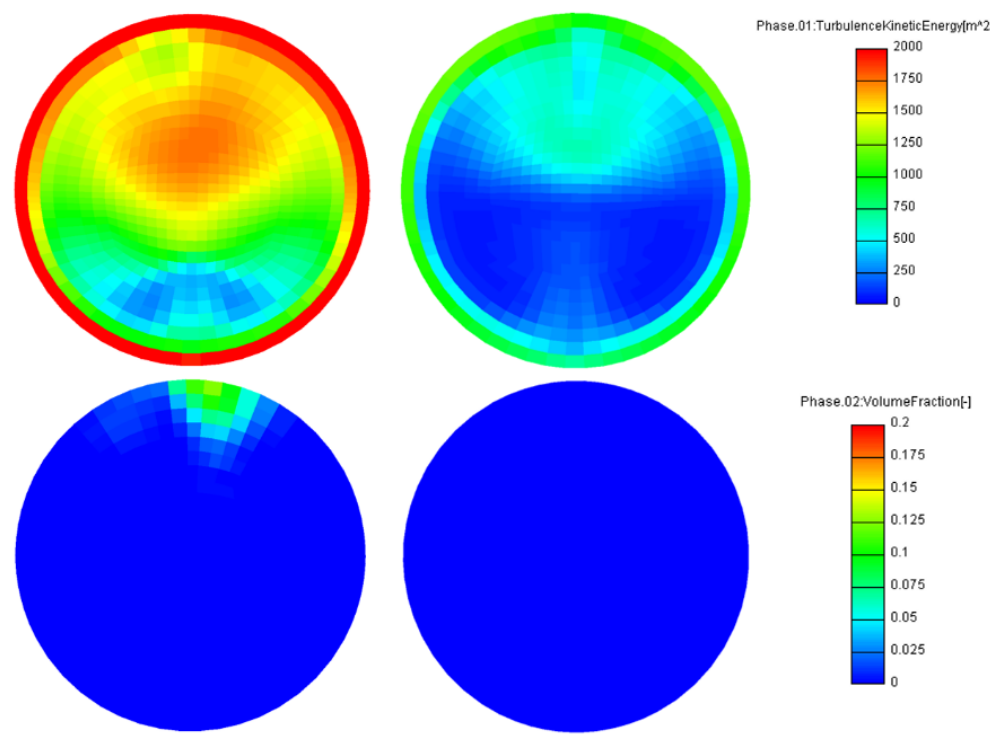

Figure 8. Turbulent kinetic energy and vapour volume fraction at nozzle outlet for diesel case (Left) and for HFO (Right)

\section{Modification of the 1D-modell to predict the HFO-spray tip penetration}

Figure 9 presents the measured spray tip penetration of the HFO by 1600 and 1800 bar injection pressure and $33 \mathrm{~kg} / \mathrm{m}^{3}$ gas density and of diesel at the same density. The results are plotted in the mass domain. As can be seen from this figure, the HFO curves are nearly identical, which confirms that the first phenomenon of the 1D-Model is also valid for HFO. From the same figure is to be noticed that the HFO-curves differ from the diesel one. This means that the parameter $(a)$ and $(b)$ in equation 1 should be modified for HFO case. The new values for $(a)$ and $(b)$ are 275 and 0.37 respectively.

To calculate the influence of the gas density on the spray penetration in HFO-case a spray penetration at gas density $\rho_{1}$ has been plotted over another one at different gas density $\rho_{2}$ but at the same cumulated injected mass 
(similar to Figure 4). The correlation between the sprays is linear and has the same slope like in diesel case, which means that the influence of the gas density on the spray tip penetration is the same for both fuels and do not depend on the fuel properties, Figure 10.

Figure 11 contains a representative selection of spray penetrations at different operating points, calculated from the measured injection rates using modified parameters for HFO and measured directly within the high-pressure injection chamber. As the comparison shows, the calculated and measured data agree very well.

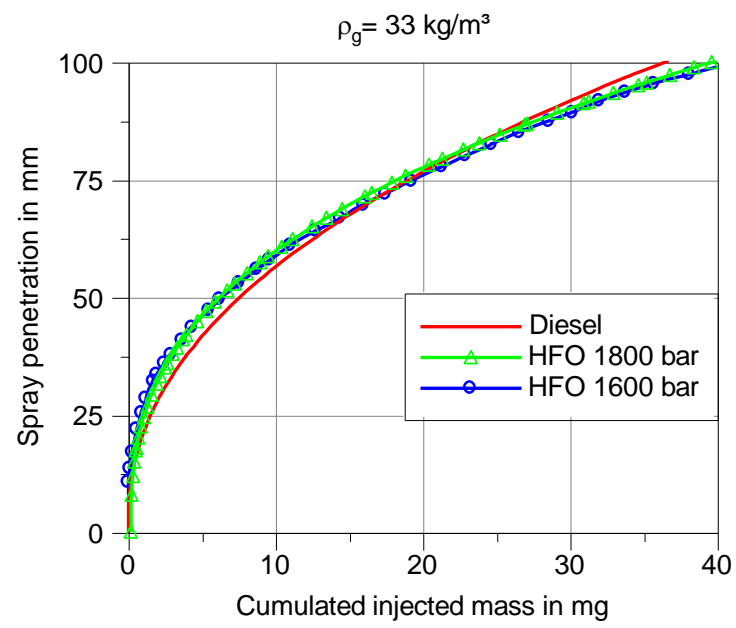

Figure 9. Spray tip penetration against the cumulated injected mass for diesel and HFO

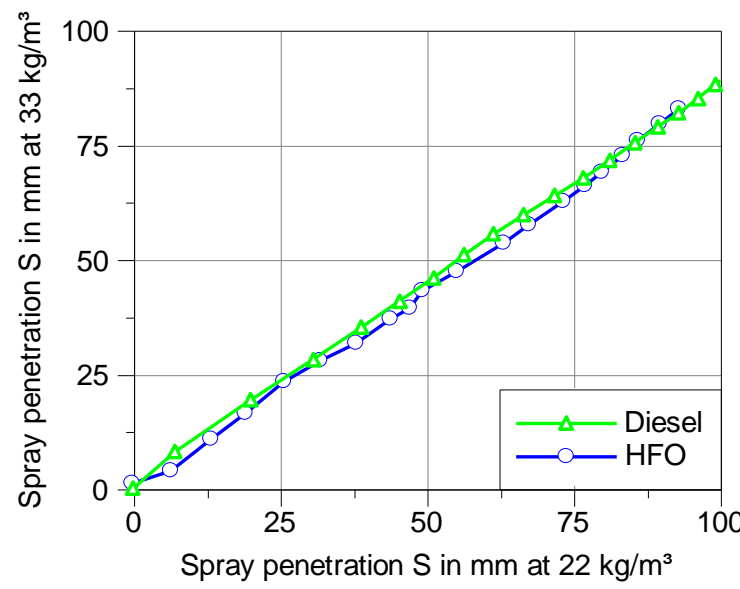

Figure 10. Correlation of spray penetrations at different gas densities at times of equal cumulated mass for diesel and HFO
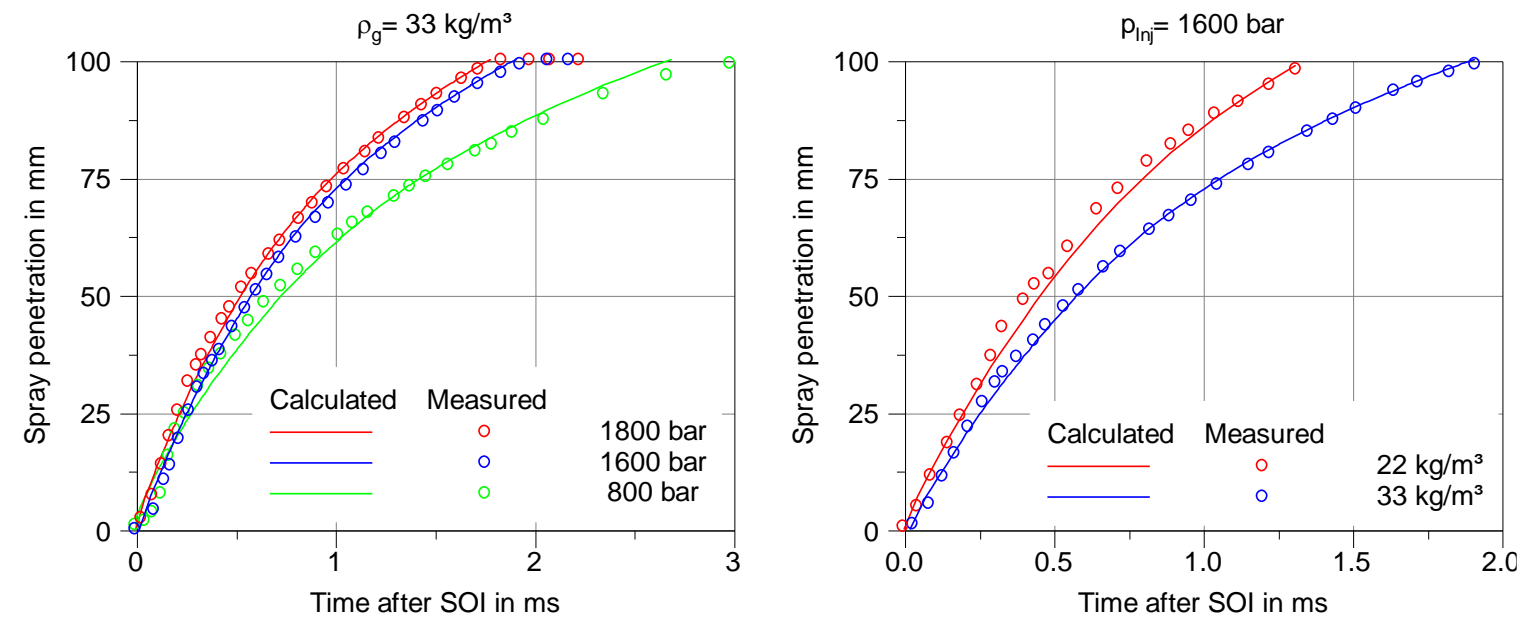

Figure 11. A comparison between the calculated and measured HFO-spray penetration for different injection pressure at 33 $\mathrm{kg} / \mathrm{m}^{3}$ gas density (Left) and for two gas densities at 1600 bar injection pressure (Right) 


\section{Prediction of spray tip penetration at fuel with different fuel temperature}

Temperature dependency of diesel properties is known and investigated by several researchers e.g. [10] and [11]. As the temperature increases both the fluid density and viscosity decrease. This leads to an enhanced break up because of the high value of Weber number [12]. In [12] the authors studied numerically the influence of the fuel temperature on the spray length. To calculate the tip penetration under different fuel temperatures the authors in [12] assumed that the parameters $(b)$ and $(c)$ are temperature independent and suggested a simple correlation to predict the parameter $\left(a_{T}\right)$ at fuel temperature $\mathrm{T}$ as a function of $(a)$ and Weber number at a reference temperature $T_{0}=313 \mathrm{~K}$, equation 3 .

$$
a_{T}=a_{T_{0}} \cdot \sqrt{\frac{W e_{T_{0}}}{W e_{T}}}=a_{T_{0}} \cdot \sqrt{\frac{\rho_{T_{0}}}{\sigma_{T_{0}}} \cdot \frac{\sigma_{T}}{\rho_{T}}}
$$

To validate this equation for diesel fuel experimental data from Engine Combustion Network (ECN) are used. The measured data are located on [13]. On the home page a numerous experimental data with different parameter like fuel type, nozzle hole diameter, gas density and temperature are available. Figure 12 presents a comparison between the data from ECN at fluid temperature of $450 \mathrm{~K}$ and using equation 1 and 3 calculated spray length. Using equation 3 the calculated value of $\left(a_{T}\right)$ is 225. The left diagram in Figure 12 shows the good agreement between ECN and calculated curves for different nozzles. This high ability to calculate the penetration for different nozzles is explained by considering the injection rate and thus the injector dynamic within the opening phase. Further comparisons, carried out at 1400 bar injection pressure, $0.33 \mathrm{~mm}$ outlet diameter of the injection hole and different gas densities confirm the high accuracy of the model, see the right diagram in Figure 12.
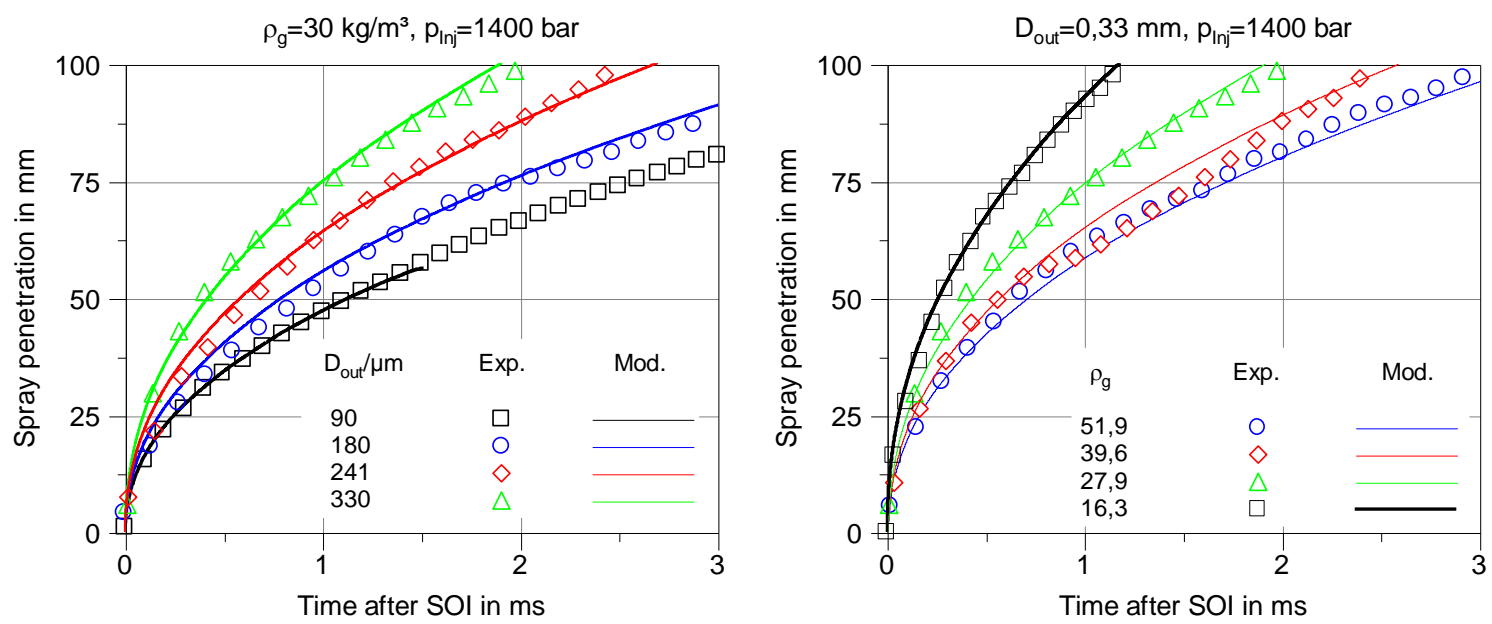

Figure 12. Measured and calculated spray penetration for different nozzles (Left) and various gas densities (Right)

\section{Conclusions}

In the course of the development of an engine, combustion engineers have great interest in a simple mean to predict the spray penetration within the cylinder. A flow rate analyser has been used to understand the hydraulic behaviour of the injector under different fuels. The influence of fuel on the mixture formation under none evaporating conditions has been studied using a high-pressure/high-temperature chamber of the Institute of Piston Machines and Internal Combustion Engines at Rostock University. The measurements emphasize that the fuel properties influence the spray break up and furthermore the spray length and cone angle.

To calculate the spray length with HFO an existing model has been modified and used. This model is originally developed for diesel sprays from large injectors and is based on two phenomena which include in particular the behaviour of the spray in mass domain and the correlation between two sprays at different gas densities. At the beginning these two phenomena have been verified for the HFO. The results show that the influence of the gas density on the spray length is independent from the fuel type. On the other hand the two other parameters which describe the influence of the fuel properties on the break-up had to be modified. Using the new values of these parameters sprays at various rail pressures and gas densities could be calculated for HFO. The results agree very well with the measurements. Because of the strong influence of the fluid temperature on the fuel properties and therefore on the spray penetration a correlation to calculate the first parameter in the model $(a)$ is investigated. The results has been validated utilizing experimental data from ECN. The comparison shows the high prediction accuracy of the model for a wide range of conditions. 
Furthermore the influence of the fuel type on the spray cone angle is experimentally investigated. To explain the results a 1D-model of the measured injector was coupled with a 3D-CFD-simulation of the nozzle internal hole. Because of the low values of the turbulent kinetic energy and Weber number HFO-spray-core will be much more compact than by diesel, which leads to poor air entrainment in the spray and to a smaller spray cone angle.

\section{Acknowledgements}

The presented results are part of the research project "Multiple Injection Strategies for Optimizing Mixture Formation and Combustion in Large Diesel Engines to meet lowest $\mathrm{CO}_{2}$ and Pollutant Emissions using Maritime Fuels". We would like to thank the German Research Fondation (DFG) for funding this project. We would also like to thank Bosch company for their assistance.

\section{Nomenclature}

\begin{tabular}{|c|c|c|c|}
\hline$a, b$ and $c$ & model coefficients & $T$ & fuel temperature $[\mathrm{K}]$ \\
\hline$a_{T}$ & model coefficient $(a)$ at fuel temperature $\mathrm{T}$ & $T_{g}$ & gas temperature $[\mathrm{K}]$ \\
\hline$D_{\text {out }}$ & hole outlet diameter & $\rho_{f}$ & fuel density $\left[\mathrm{kg} / \mathrm{m}^{3}\right]$ \\
\hline$S$ & spray tip penetration [mm] & $\rho_{g}$ & gas density $\left[\mathrm{kg} / \mathrm{m}^{3}\right]$ \\
\hline$S_{\rho_{g}}$ & $\begin{array}{l}\text { spray tip penetration at gas density } \rho_{g} \\
{[\mathrm{~mm}]}\end{array}$ & $m_{f}$ & $\begin{array}{l}\text { cumulated injected mass from one nozzle } \\
\text { hole [mg] }\end{array}$ \\
\hline$Q_{\text {hyd }}$ & $\begin{array}{l}\text { hydraulic flow rate from one nozzle hole } \\
{\left[\mathrm{cm}^{3} / 30 \mathrm{~s} @ 100 \text { bar }\right]}\end{array}$ & $p_{\text {Inj }}$ & injection pressure [bar] \\
\hline $\mathrm{CO}_{2}$ & Carbon dioxide & $W e$ & Weber number [-] \\
\hline$N O_{x}$ & Nitrogen oxide & $\sigma$ & surface tension $[\mathrm{N} / \mathrm{m}]$ \\
\hline$N E C A s$ & $\mathrm{NO}_{x}$ Emission Control Areas & $D K$ & diesel fuel \\
\hline$E C N$ & Engine Combustion Network & HFO & heavy fuel oil \\
\hline SOI & Start of Injection & & \\
\hline
\end{tabular}

\section{References}

[1] Najar, I., Fink, C., Pinkert, F., Harndorf, H., 2014, October 2014, 26th European Conference on Liquid Atomization and Spray Systems

[2] Gostic, I., Senghaas, C., Willmann, M., Wensing, M., September 2010, 23th European Conference on Liquid Atomization and Spray Systems.

[3] Hüttl, C., Leidenberger, U., Brüggemann, D., September 2010, 23th European Conference on Liquid Atomization and Spray Systems.

[4] Heilig, A., Kaiser, M., Dinkelacker, F., Sep. 5.-7. 2011, 24th European Conference on Liquid Atomization and Spray Systems.

[5] Grimaldi, C., Postrioti, L., SAE Technical Paper 2000-01-1252, 2000, doi: 10.4271/2000-01-1252.

[6] Rostock University, BMWi-Project, Fuel and Air Management for Emission reduction, Final report

[7] Fink, C., Rabe, J. R., Drescher, M., Harndorf, H., Sep. , 2012, $2^{\text {nd }}$ Rostocker Großmotorentagung

[8] Bosch, W., 1964, , MTZ-MotortechnischeZeitschrift, 25(7)

[9] Fink, C., Pinkert, F., Harndorf, H., Sep. 5.-7. 2011, 24th European Conference on Liquid Atomization and Spray Systems.

[10] Payri, R., Salvador,F.J., Gimeno, J., Bracho, G., Fuel 90 (2011) 1172-1180

[11] Safarov, J., Hassel, U., Shahverdiyev, 27-29 June 2017, 11th International Colloquium Fuels

[12] Najar I., Fink, C., Stengel, B., Buchholz, B., Drescher, M., Harndorf, H., Hassel, E., March. 16.-17. 2017. $13^{\text {th }}$ Engine combustion processes

[13] Engine Combustion Network, https://ecn.sandia.gov/ecn-data-search/?nam=1

[14] Dernotte, J., Hespel, C., Foucher, F., Houillé, S., Mounaïm-Rousselle, C., Sep. 5.-7. 2011, 24th European Conference on Liquid Atomization and Spray Systems.

[15] Desantes, J., Arrègle, J., Pastor, J., Delage, A., SAE Technical Paper 980802, 1998, doi:10.4271/980802

[16] Desantes, J., Payri, R., Garcia, A., Manin, J., Energy \& Fuels, 23 (6) (2009) 3227\{3235, ISSN 0887-0624, doi:nbibinfofdoigf10.1021/ef801102wg.

[17] Payri, R., Salvador,F.J., Carreres, M., De la Morena, J., Energy Conversion and Management 114 (2016) 376\{391, ISSN 01968904, doi:nbibinfofdoigf10.1016/j.enconman.2016.02.043g.

[18] Chang, C., Farrell, P., SAE Technical Paper 970353, 1997, doi:10.4271/970353.

[19] Naber, J. and Siebers, D., SAE Technical Paper 960034, 1996, doi:10.4271/960034. 